University of Nebraska - Lincoln

DigitalCommons@University of Nebraska - Lincoln

Community and Regional Planning Program:

Faculty Scholarly and Creative Activity

Community and Regional Planning Program

$10-2012$

\title{
Developing a Restorable Wetland Index for Rainwater Basin Wetlands in South-Central Nebraska: A Multi-Criteria Spatial Analysis
}

\author{
Zhenghong Tang \\ University of Nebraska - Lincoln, ztang2@unl.edu \\ Xu Li \\ University of Nebraska-Lincoln, xuli@unl.edu \\ Nan Zhao \\ University of Nebraska-Lincoln \\ Ruopu Li \\ University of Nebraska-Lincoln, rli3@unl.edu \\ F. Edwin Harvey \\ University of Nebraska-Lincoln
}

Follow this and additional works at: https://digitalcommons.unl.edu/arch_crp_facultyschol

Part of the Biodiversity Commons, Bioresource and Agricultural Engineering Commons, Terrestrial and Aquatic Ecology Commons, and the Urban, Community and Regional Planning Commons

Tang, Zhenghong; Li, Xu; Zhao, Nan; Li, Ruopu; and Harvey, F. Edwin, "Developing a Restorable Wetland Index for Rainwater Basin Wetlands in South-Central Nebraska: A Multi-Criteria Spatial Analysis" (2012). Community and Regional Planning Program: Faculty Scholarly and Creative Activity. 15.

https://digitalcommons.unl.edu/arch_crp_facultyschol/15

This Article is brought to you for free and open access by the Community and Regional Planning Program at DigitalCommons@University of Nebraska - Lincoln. It has been accepted for inclusion in Community and Regional Planning Program: Faculty Scholarly and Creative Activity by an authorized administrator of DigitalCommons@University of Nebraska - Lincoln. 
Published in Wetlands: Official Scholarly Journal of the Society of Wetland Scientists, vol. 32, iss. 5 (October 2012), pp. 975-984;

doi: 10.1007/s13157-012-0320-x; erratum doi: 10.1007/s13157-012-0329-1

Copyright () 2012 Society of Wetland Scientists; published by Springer Verlag. Used by permission.

Submitted January 3, 2012; accepted June 20, 2012; published online July 17, 2012.

\title{
Developing a Restorable Wetland Index for Rainwater Basin Wetlands in South-Central Nebraska: A Multi-Criteria Spatial Analysis
}

\author{
Zhenghong Tang, Xu Li, Nan Zhao, Ruopu Li, and F. Edwin Harvey \\ University of Nebraska-Lincoln, Lincoln, NE, USA \\ Corresponding author - Zhenghong Tang, email ztang2@unl.edu
}

\begin{abstract}
It is always challenging for decision makers to prioritize wetland conservation programs at the landscape scale. This study employed a GIS-based multi-criteria spatial decision support tool that identified locations with the highest restoration potential for wetland conservation programs in the Rainwater Basin in south-central Nebraska. Five indicators were considered to assess wetland restoration potential: (1) Vegetation characteristics; (2) Soil characteristics; (3) Water volume released from hydrological modification of agricultural irrigation pits; (4) Topographical depression status; and (5) Habitat condition. The results suggested 192 (1.6\% of the total) hydric soil footprints as the highest prioritized locations for future wetland restoration programs. The results also identified 901 footprints $(7.7 \%$ of the total) with medium-high restoration potential, 1,792 (15.2\% of the total) footprints with medium-low restorable potential and 8,875 (75.5\% of the total) footprints with low restorable potential. The methodology and statistical results contribute directly to the state's Rainwater Basin Wetland Program Plan and are potentially applicable to the management of other wetlands across the region and globally.
\end{abstract}

Keywords: wetland restoration, restorable wetland index, RWI, wetland program plan, GIS, decision making tool

\section{Introduction}

Wetland restoration usually refers to "the rehabilitation of wetlands that may be degraded or hydrologically altered and often involves reestablishing the vegetation" (Mitsch and Gosselink 1993). Wetland restoration means the manipulation of an historical or a degraded wetland's physical, chemical, or biological characteristics to return its natural conditions (LaGrange 1997). Wetland restoration has been recognized as an essential strategy for reversing wetland loss and enhancing wetland func- tion and integrity (Flanagan and Richardson 2010). Although significant restoration efforts have been made in the past decades, many wetlands still face degradation across the landscape. However, wetland restoration decisions are typically made on a project-by-project basis rather than at a landscape level (White and Fennessy 2005; Voss 2007). Although project-specific goals and strategies are critical, restoration programs should be designed holistically from an ecosystem perspective. For example, most wetland programs focused solely on the wetland at a site level, and did not pay special attention to drainages linking with wetlands. Wetland restoration programs over-emphasized recovering wetland water bodies, but gave less emphasis to restoring entire wetland hydrologic systems. However, hydrologic linkages between wetlands and their landscapes are equally important in prioritizing wetland restoration sites (Bedford 1996; Galatowitsh et al. 1998; White and Fennessy 2005).

It is always challenging for decision makers to integrate scientific knowledge in efforts to prioritize wetland restoration programs amongst a large number of wetlands at the landscape scale. A critical need is to establish a systematic procedure to prioritize wetlands for restoration efforts. An holistic understanding of the ecosystem in its natural state is necessary to allocate effective wetland restoration programs (Steyer et al. 2003; Simenstad et al. 2006; Montgomery 2008; Stein et al. 2010). Wetland restoration decision-making should identify appropriate locations in the landscape to reestablish the structure, function, and integrity of the wetland ecosystem. Wetland restoration has the best chance of success if the ecosystem function is considered at both the site and landscape scales (NRC 2001) and priority is given to wetlands with the highest potential to succeed (Galatowitsh et al. 
1998). To achieve this goal, a critical research question needs to be answered: What criteria should be used to determine the potential of a site for successful restoration? Due to time and budget constraints, wetland conservation programs typically focus on restoring the wetlands' communities, and not on implementing a full restoration of the wetlands' hydrology.

Both qualitative and quantitative approaches are used widely for wetland restoration planning and site prioritization. A common qualitative approach is to rely on an expert's experiences and local knowledge to prioritize wetland sites. Quantitative approaches seek either guaranteed optimal solutions or non-guaranteed solutions in restoration decisions (Possingham et al. 2000; Stralberg, et al. 2009). Cedfeldt et al. (2000) developed a methodology to estimate spatial predictors of wetland functions. Lin and Kleiss (2007) used hydric soils, a wetness index, and the distance to seed source to describe the restorability of an area to a functional and sustainable wetland. Flanagan and Richardson (2010) used both regional and watershed-level water quality decision tree models to prioritize wetland restoration locations in the Harrison Creek watershed in eastern North Carolina. Jacobs et al. (2010) developed a quantitative Index of Wetland Conditions (IWC) to evaluate wetland condition in the Nanticoke Watershed in the US.

A significant trend of wetland restoration assessment is the use of Geographic Information System (GIS) in a landscape analysis. GIS provides robust spatial analysis able to effectively incorporate landscape-scale parameters, such as distribution and abundance of wetlands into assessments (Dahl 2006; Liu et al. 2006). A number of critical physical characteristics, such as hydrology, geomorphology, soils, topographical variations, and land use, should be evaluated appropriately for site selection of potential wetland restoration programs (Bedford 1996; O'Neill et al. 1997; Russell et al. 1997). The GIS-based assessment approach can serve as the basis of a spatially explicit and flexible wetland management decision support tool to prioritize wetlands for restoration.

The objective of this study was to develop a Restorable Wetland Index (RWI) to prioritize future restoration programs for the large number of playa wetlands in the Rainwater Basin region of South-central Nebraska, USA. The RWI can be defined as a ranking system with a set of measurable indices to prioritize wetlands for restoration. The RWI is assessed by its ability to determining the suitability of a location to sustain a functional wetland. The RWI can serve as a criterion for future on-site feasibility studies of wetland restoration. This study employed GIS to analyze historic hydric soil footprints for potential restoration, and made a prioritization rank according to the likelihood of restoration success. The framework of the RWI is transferable to other regions for a landscape-scale wetland assessment and prioritization.

\section{Study Area}

The study area was the Rainwater Basin Wetland region of south-central Nebraska, which encompasses $15,907 \mathrm{~km}^{2}$ across 21 counties (Figure 1). Playa wetlands in the Rainwater Basin are internationally significant ecological areas for migratory birds of the Central Flyway. The Rainwater Basin serves as the focal point for millions of migratory waterfowl each spring. Playa wetlands in the Rainwater Basin were identified as a critical wetland area for conservation in the USA (Haukos and Smith 1994). Playa wetlands in the Rainwater Basin region are shallow seasonal wetlands with important ecological functions, including flood mitigation, capturing and filtering surface runoff, recharging the underlying aquifer, and enhancing biodiversity (LaGrange 1997). As agriculture production expanded over the past several decades, over $85 \%$ of the historic wetlands were lost or degraded. Major threats to playa wetlands are expansion of irrigated land, excavation for irrigation collection and drainage pits or agricultural modifications, and culturally accelerated sedimentation. It is believed that without strategic conservation actions these wetlands will continuously lose wetland functions.

\section{Selection of the Target Data: SSURGO or NWI}

Two data layers-historic hydric soil footprint data from the Soil Survey Geographic (SSURGO) database and National Wetland Inventory (NWI) data from the U.S. Fish and Wildlife Service, are often used by federal, state, and local wetland management agencies in making management decisions. The historic hydric soil footprint layer contains only playa depressional wetlands, which are the predominant type of wetland in the Rainwater Basin. In contrast, the NWI data contain all types of wetlands: excavated pits, stock ponds, reservoirs, wet meadows, river channels, emergent marshes, riparian shrub lands, and canopies. Most of the time, federal and state wetland management programs are not particularly interested in the NWI features that do not pertain directly to wetlands in the Rainwater Basin. For example, while man-made features such as pits contribute to the overall landscape that wildlife use; wetland management program managers who work in this area do not consider these features wetlands. Another difference between the two layers is that the NWI layer includes only currently functional wetlands, whereas the hydro soil wetland layer also includes historically functional wetlands. In addition, the Natural Resources Conservation Service (NRCS) delineates wetland restoration projects using soils where they are prohibited from performing wetland restorations outside of the hydric soil footprint. Because NRCS is a major source of funding for private lands projects, soil data is used almost exclusively by the Rainwater Bain Joint Venture (RWBJV) 


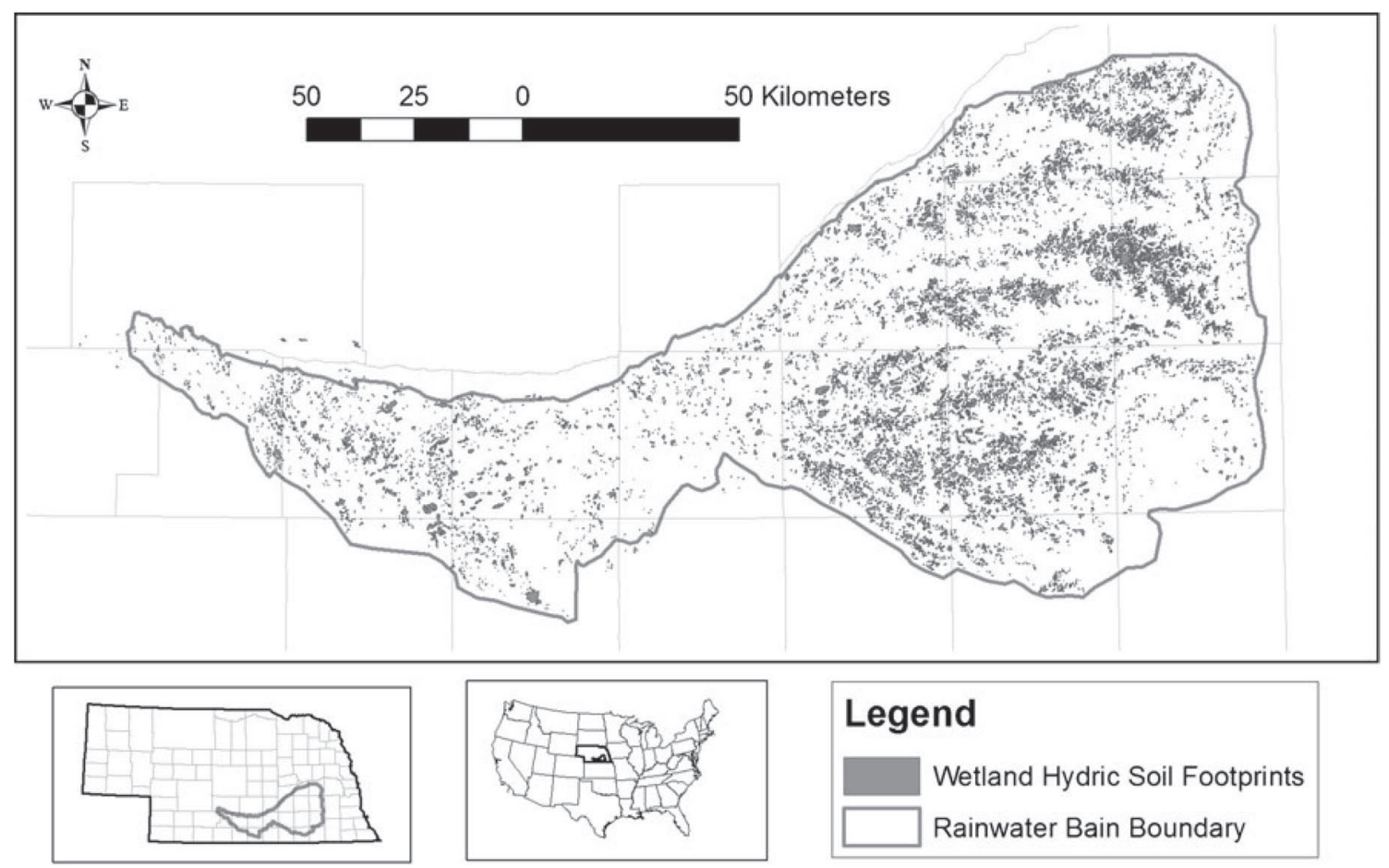

Figure 1. Playa wetland hydric soil footprints Rainwater Basin in South-central Nebraska.

and Nebraska Game and Parks Commission (NGPC) (at least among the private land divisions) to identify wetlands. Therefore, after consulting RWBJV and NGPC, this study decided to use historic hydric soil footprint data layer, rather than the NWI data layer, as the target layer to calculate the RWI.

\section{Assumptions of the Multi-criteria Evaluation Method}

Fennessy et al. (2007) suggested that one overall score is more preferable to multiple functional scores in wetland assessment. Thus, this study opted to develop a single score RWI to assess wetland restorability. A quantitative, multi-criteria spatial assessment approach is used to generate a set of indicators to prioritize wetland restoration. Multi-criteria evaluation has been used widely in planning, policy analysis, and environmental management (Carver 1991a, b; White and Fennessy 2005). The site selection methodology of the restorable wetlands in this study is based on multiple-criteria evaluation theory in a GIS framework to identify sites with the highest restoration potential. This study employed a multi-criteria assessment approach to score each wetland's conditions. A GIS-based decision support tool was developed to predict the suitability for wetland restoration of all hydric soil footprints in the Rainwater Basin. The RWI can provide a scientific means of conveying concisely wetland conditions at the site or landscape level. The RWI is a valuable tool to map wetland condition information in a spatially explicit way for wetland managers who are interested in assessing wetland conditions.
Two assumptions were made in the RWI calculation. First, all historical wetland footprints have a $50 \%$ opportunity to be restored to their functional levels. If the scale from the lowest level of $0 \%$ to the highest level of $100 \%$ can be used to measure the restorability, then $0 \%$ means the wetland is un-restorable. However, the target lands in this study are the historic hydric soil footprints. Since these lands were historic wetlands in the 1927's and 1980's Soil Survey, technically, all of the historical hydric soil footprints can be restored to the previous wetland conditions with a 50\% chance, rather than the lowest chance of $0 \%$ restorability. Thus, the first assumption reflects the history of these lands and the potential restoration abilities. Ideally, all historical wetlands should be considered for restoration resulting in clusters of wetland complexes, from small to large, from ephemeral to permanent, and from shallow to deep water (Galatowitsh et al. 1998). Second, wetland restoration priorities should be given to footprints with suitable conditions (but not currently in any conservation programs). A suitable condition considers vegetation, soil, hydrology, or other factors. Wetlands with a high RWIs have an excellent chance for successful restoration and thus can provide dramatic benefits to the ecosystem. These assumptions are essentially consistent with the RWBJV's working priority, which is mainly built on hydric soil footprints and jurisdiction/conservation statuses (Bishop 2010). Wetland restoration and prioritization programs should pay particular attention to the areas with high density, functioning wetlands with optimal juxtaposition between wetland types (Bishop and Vrtiska 2008). This assumption ensures 
the greatest benefit for the given cost of future wetland restoration programs in these wetlands.

\section{Criteria and Indicators of the Restorable Wetland Index}

This study developed criteria, indicators, and protocols to calculate the RWI. The criteria and indicators considered include wetland physical characteristics (e.g. soil character, vegetation character) and landscape-scale ecological parameters (e.g. hydrologic regime, topographic characteristics, and habitat conditions). Wetland characteristic variables (i.e., hydric soils, hydrology, and wetland vegetation) are used widely to define a wetland's sustainability and ability to be a functioning wetland (Environmental Laboratory 1987). This study only considered the physical variables that could affect wetland restoration, and did not include socioeconomic variables, such as construction costs and land ownership, due to their uncertainty. The objective of the RWI is to provide a scientific description of each wetland's physical conditions that can be used as a critical scientific reference to implement future wetland restoration programs.

\section{Vegetation Characteristics}

Vegetation plays a critical role in wetland function (Bishop 2010). Vegetation type is used to predict wetland functions in order to identify which wetlands lack adequate protection and where habitat gaps occur (Galatowitsh et al. 1998). Wetland vegetation serves as a food source for wildlife including migratory birds. Vegetation data was captured from the vegetation GIS layer from the RWBJV. Vegetation types for playa wetlands in the Rainwater Basin include cattail (Typha latifolia), bulrush (Scirpus spp.), reed canary grass (Phalaris arundinacea), agriculture, stressed agriculture, grass, trees, and others. Thus, in this study, higher scores were given to those footprints with higher percentages of hydrophyte vegetation.

\section{Soil Characteristics}

The presence of hydric soils is a critical indicator that an area was formerly or is currently a wetland resulting from repeated periods of saturation or inundation (Starks 1984; O' Hara et al. 2000; Lin and Kleiss 2007; LaGrange et al. 2011). Favorable soil conditions (e.g. hydric soils) are adopted as a criterion to identify potentially restorable wetlands (Voss 2007). A site with potential for wetland restoration should have soils capable of supporting a water body. This study used the USDA Natural Resource Conservation Service (NRCS) Soil Survey Geographic (SSURGO) data layer and associated soil properties tables. SSURGO depicts soil classification information about the distribution and types of soils. In this study, hydric soils, which are more conducive to sustaining wetlands than non-hydric soils, were given a higher score. Thus, in this study, wetland restoration priorities should be given to the footprints with relatively wetter soil types (e.g. Massie, Fillmore) that usually have high water holding capacity.

Water Volume Released from Hydrological Modification of Agricultural Pits

Pits are used to collect and impound water on gravityirrigated lands where pivot irrigation systems are not available. Topographically, most of the pits were naturally located in the lower elevation areas to maximally collect runoffs from the uplands. A majority $(60 \%)$ of the cropland in the Rainwater Basin uses the central pivot irrigation system, and thus, the majority of the reuse pits are no longer used to collect rainwater runoffs for agricultural irrigations (Robichaux 2010). Yet many pits still remain and are in use across the region. Restoration by filling reuse pits can reduce the amount of runoff capture and thus make available a significant portion of runoff water that can go to improve existing wetlands. Pits collect tail water and allow the farmers to maximize water use for crop growth. Pits hold irrigation runoff until they reach full storage capacity. However, because these pits could hold a significant amount of water, they change the Rainwater Basin's hydrological system and reduce wetland capacity (Stutheit et al. 2004). A recent survey identified 10,217 pits within the Rainwater Basin and estimated that at least 42.6 million cubic meters of water at full pool could be held in these pits (Bishop and Vrtiska 2008). These pits store a significant amount of runoff that would otherwise have been used to fill wetland footprints. Because most of the Rainwater Basin's agricultural lands are being converted from existing gravity irrigation systems to pivot irrigation systems, irrigation tailwater pits can be filled to restore and enhance the hydrology of the playa wetlands (USNRCS 2008). The off-site pit restoration approach helps reconstruct the Rainwater Basin's pre-development hydrologic function and connectivity. Filling irrigation reuse pits can have the most profound impact to improve wetland hydrology (Robichaux and Harrington 2009). There are substantial potentials for releasing the runoff back to the watershed if these pits no longer capture the runoff. Irrigation reuse pit closure has been identified as a priority practice in the Wetland Program Plan for Nebraska (LaGrange 1997; Bishop and Vrtiska 2008). Thus, in this study, wetland restoration priorities should be given to footprints with large water volumes from modified agricultural irrigation reuse pits, which can have higher potentials to release more surface water.

\section{Topographic Depression Status}

Topographic-based saturation can be used as a measure of the function of the surface hydrology of a watershed 
(White and Fennessy 2005). The topographic-based depression condition indicates the ability of surface water to accumulate in order to estimate restoration potential. The topographical depression is the key factor in deciding the potential likelihood of a full hydrologic restoration for wetlands. This study used a LiDAR-derived digital elevation model to calculate each footprint's flow accumulation status. The topographic depression indicates an area at a lower elevation than all other immediately surrounding areas (Lin and Kleiss 2007). Topographic depressions retain runoff water. Areas within topographic depressions, therefore, are given a higher score, and areas outside of topographic depressions are given a lower score. Thus, in this study, wetland restoration priorities should be given to the footprints with relatively lower topographical depression land areas that can accumulate runoff.

\section{Habitat Condition}

Playa wetlands across the Rainwater Basin region offer critical ecological values to the migratory birds of the Central Flyway. The habitat surrounding wetlands provides a great benefit to wildlife, increases hydrologic connectivity, and maintains water quality and quantity (Kramer and Elliott 2005). The habitat condition assesses the wetland potential for the peak period of spring bird migration. Habitat information is useful for identifying locations where restoration could provide a critical enhancement of existing wetlands and also to provide guidance on prioritizing restoration efforts for specific areas (Galatowitsh et al. 1998). The RWBJV's Annual Habitat Survey (AHS) produced the habitat condition data used in this study. The AHS collected aerial photography over the entire Rainwater Basin region in early March of 2004, 2006, 2007, 2008, and 2009. No aerial photography was collected in March 2005 (Robichaux 2010) and thus, this data was not available for this study. A field survey was conducted to verify the accuracy and consistency of the interpretation of the aerial photos. The habitat conditions were recorded in an ArcGIS vector-based shape file format with accompanying attribute tables. Each polygon incorporates information on ponded water, vegetation, and moist soil conditions.

\section{Methods for Calculation of RWI}

This study used the simple linear-weight summation calculation to count the variables that may influence wetland restoration. The scoring system was used recently by White and Fennessy (2005) to depict wetland restoration qualitatively. ArcGIS 10 was used to calculate the RWI scores for each footprint. These five criteria were assigned a value on a scale from 0.5 to 1.0. The criteria's scores were accumulated from the variables that influence wetland restoration, and were standard- ized to each hydric soil footprint. The minimal possible RWI score of a footprint was 2.5 and the maximum possible RWI score of a footprint was 5.0. Each historic hydric soil footprint in the study area was assigned a score for each criterion. The final Restorable Wetland Index (RWI) scores were the sum of the five indices' scores (see Equation 1).

$$
\mathrm{RWI}=V_{1}+S_{2}+W_{3}+T_{4}+H_{5}
$$

RWI: Restorable Wetland Index score; $V_{1}$ : Vegetation Characteristics score; $S_{2}$ : Soil Characteristics score; $W_{3}$ : Water Volume score; $T_{4}$ : Topographic Depression status score; $\mathrm{H}_{5}$ : Habitat condition score.

$V_{1}$ - The vegetation characteristic score $\left(V_{1}\right)$ is measured by the standardized percentage of a certain type of hydrophyte vegetation in each footprint. The vegetation types were categorized as one of three levels of scores. The first category was the hydrophyte vegetation or visible water body. This group contained cattail, scirpus, water mudflat, wet meadow, and pit and was scored 1.0 as the most desirable vegetation type. The second category was scored as 0.75 , indicating a medium-level of hydrophyte vegetation types. This group included the relative wetlands containing hydrophyte vegetation types, such as moist soil and reed canary grass. Reed canary grass is invasive plant in most types of wetlands. It grows well on moist organic soils in full sun. The third category was scored as 0.5, meaning a low-level of hydrophyte vegetation types. This group included agriculture, stressed agriculture, grass, and other types. These are working landscapes that have been changed from their original/natural state. In addition, trees may withdraw a large amount of water from a wetland. The vegetation percentage score $\left(P_{\mathrm{V} 1}\right)$ was standardized with quantile breaks as the final vegetation characteristic score $\left(V_{1}\right): 1.0 ; 0.9$; $0.8 ; 0.7 ; 0.6$; and 0.5 .

$$
\begin{aligned}
P_{V 1} & =\sum \frac{\text { A vegetation type score } * \text { the area of a vegetation }}{\text { A footprint area }} \\
V_{1} & =\text { the Quantile break of } P_{V 1}
\end{aligned}
$$

$S_{2}$ - The soil characteristics score $\left(S_{2}\right)$ is calculated using the standardized percentage of a certain type of soil in each footprint. The soil data layer was captured from the attribute table of the SSURGO soil database and RWBJV's field verification. The soil types were categorized as one of three levels of scores based on the description of soil series report by U.S. Fish \& Wildlife Service (USFWS 1987). The first category includes a visible water body, with intermittent water, and/or marsh that can be frequently or continually inundated with water. 
These soil types could be scored as the most suitable level with a score of 1.0. The second category includes the Massie soil series (Massie Silt Loam, Massie silty clay loam) and Fillmore soil series (Fillmore Silt Loam and Fillmore Silty Clay Loam). According to the soil classifications, the Massie layer is a very poorly drained claypan soil formed in loess modified by water in the lowest, wettest depressions or basins of uplands. The Massie soil layer is normally below Scott and Fillmore series in the landscape. Fillmore layer is a poorly drained claypan soil formed in loess in shallow depressions or basins of uplands and stream terraces. The Fillmore layer is normally above Massie and below Butler series in the landscape. These soils in the second category are scored as a medium-level score of 0.75 . The third category includes Scott soil series (Scott Silt Loam and Scott Silty Clay Loam), Bulter (Butler Silty Clay Loam; Butler-Slickspots Complex), Aquolls, and other types. The Scott layer is a very poorly drained claypan soil formed in loess or loess modified by water in the lower parts of depressions or basin of uplands. The Scott layer is normally above Massie and below Butler series in the landscape. The Butler layer is somewhat poorly drained soils formed in loess or mixed loess and alluvium on uplands and high stream terraces. The Bulter layer normally occurs above Scott and Fillmore Series in the landscape. The Aquolls layer is relatively wet and that have dominant low chroma. These soils in the third category are scored as a low-level score of 0.5 . The percentage score of soil characteristics $\left(P_{\mathrm{S} 2}\right)$ for each footprint were standardized with quantile breaks as the final soil characteristic score $\left(\mathrm{S}_{2}\right)$ : $1.0 ; 0.9 ; 0.8 ; 0.7 ; 0.6$; and 0.5 .

$$
\begin{aligned}
& P_{S 2}=\sum \frac{\text { A soil type score } * \text { the area of a soil type }}{\text { A footprint area }} \\
& S_{2}=\text { the Quantile break of } P_{S 2}
\end{aligned}
$$

$W_{3}$ - The water volume score $\left(W_{3}\right)$ is calculated as the ratio of a pit's volume to a footprint volume. It indicates that the effects of possible water volume releasing from hydrological modification of agricultural irrigation pits. The percentage $\left(P_{W 3}\right)$ was expressed as the following equation, and the percentages were standardized with quantile breaks for the final water volume score (W3): $1.0 ; 0.9 ; 0.8 ; 0.7 ; 0.6$; and 0.5 .

$$
P_{W 3}=\sum \frac{\text { A pit's volume in a footprint }}{\text { A footprint's volume }}
$$

$$
W_{3}=\text { the Quantile break of } P_{W 3}
$$

$T_{4}-$ The topographic depression status score $\left(T_{4}\right)$ is a standardized cumulative score for both the percentage and the absolute areas of depressional lands in a footprint. If a footprint showed any depression, it was calculated for an absolute area of the depressional lands; then quantile breaks were used to re-categorize as: $1.0 ; 0.9 ; 0.8 ; 0.7 ; 0.6 ; 0.5$. Finally, a topographic depression status score $\left(T_{4}\right)$ was standardized with Equation 9. If no depression was present in a footprint, it was scored as 0.5 .

$$
P_{T 4}=\sum \frac{\text { Depressional land area }}{\text { A footprint area }}
$$

$$
\begin{aligned}
T_{4}= & \text { (a quantile break score for } P_{T 4} \\
& + \text { a quantile break score for the absolute area } \\
& \text { of the depression lands in a footprint }) \div 2
\end{aligned}
$$

$\boldsymbol{H}_{5}$ - The habitat condition score $\left(H_{5}\right)$ is a standardized cumulative score for three habitat parameters, including the frequency of wetland functioning conditions in a footprint, the percentage of functioning wetlands in a footprint, and the absolute area of the functioning lands in a footprint. If AHS reported a footprint showing wet habitat conditions in any year between 2004 and 2009 (excluding 2005), the footprint was then assessed using three criteria : (1) The frequency of being functional according to the AHS 2004-2009 survey was assigned to a quantile break of 1.0 (functional in all 5 years); 0.9 (functional in 4 years); 0.8 (functional in 3 years); 0.7 (functional in 2 years); 0.6 (functional in 1 year); and 0.5 (nonfunctional in all 5 years). (2) The percentage of functioning area in a footprint was measured by quantile breaks as: $1.0 ; 0.9 ; 0.8 ; 0.7 ; 0.6 ; 0.5$. (3) The absolute area was measured by an actual functioning area between 2004 and 2009 with quantile breaks as: $1.0 ; 0.9 ; 0.8 ; 0.7 ; 0.6 ; 0.5$.

$$
P_{H 5}=\sum \frac{\text { Functioning habitat land area }}{\text { A footprint area }}
$$

$$
\begin{aligned}
H_{5}= & \text { (a quantile break score for the a frequency } \\
& \text { of wetland functioning conditions in a footprint } \\
& + \text { a quantile break score for the } P_{H 5} \\
& + \text { a quantile break score for the absolute area } \\
& \text { of the functioning lands in a footprint }) \div 3
\end{aligned}
$$




\section{RWI's Statistical Test}

Internal consistency is an important statistical measure for an index system to ensure that the sub-indices are describing the same target. Cronbach's alpha is the most popular method to test an index system's internal consistency based on a test of the items' mean inter-item correlation (Nunnally and Bernstein 1994). This study used Cronbach's Alpha $(\alpha)$ to assess the five indices' mean inter-item correlation with the overall RWI score. The resulting $\alpha$ value exceeded 0.81 , which is an acceptable level of reliability (Nunnally and Bernstein 1994). This testing result confirms statistically that these five indices of the RWI were internally reliable to describe the wetland conditions.

Multicollinearity (or collinearity) is another important statistical concept to measure the inter-correlations among variables. The variance inflation factor (VIF) testing was used to detect problems of multicollinearity or collinearity (Kleinman et al. 1988; Hinton 1995). The results show that all of the five indicators' VIF were between 1.026 and 2.102, which were within the statistical acceptance level of VIF $<10$. The results indicate that these five indicators have no problem with multicollinearity or collinearity.

\section{RWI's Descriptive Results}

The results show the spatial distribution of potential restoration sites ranked according to RWIs ranging from 2.5 to 3.0 (low restoration potential), 3.1-3.5 (mediumlow restoration potential), 3.6-4.0 (medium-high restoration potential), to $4.1-5.0$ (high restoration potential). Table 1 shows the distribution of the RWI in each category of wetland restoration levels.

In Table 1, the results show that only 192 footprints (1.63\% of the total) were scored with an RWI over 4.1, which indicates high restoration potentials. These wetlands with the high restorable potential (RWI > 4.1) are distributed spatially among 14 counties in the Rainwater Basin region. Clay County and York County have the largest numbers of footprints and areas that fell in this category. The results also identified 901 footprints
(7.7\% of the total) with medium-high restoration potentials, $1,792(15.2 \%$ of the total) footprints with medium-low restorable potentials, and 8,875 (75.5\% of the total) footprints with low restorable potentials. When and where resources are limited, wetlands with higher RWIs should receive higher priority for restoration. The 192 footprints with RWIs over 4.1 should be visited first for restoration feasibility studies. Additionally, each indicator provides detailed information and standardized parameter scores to help wetland managers to apply particular strategies to enhance a specific aspect of the wetland functions, which are not easily observed without field visits.

\section{RWI and Land Ownership}

There are 167 footprints located in the public areas across the Rainwater Basin region. The mean RWI for these 167 footprints is 3.65 , which fall in the range of medium-high restoration potential. Most of these footprints are already included in current wetland conservation programs. The mean of the RWI for the footprints in the private areas is 2.83 , which fall into the range for medium-low level restoration potential. In general, the RWI scores for footprints in public areas are statistically higher than those for footprints in private areas $(t=17.541, P<0.001)$. However, it is important to point out the variations in RWI of wetlands in both public and private landownership. Among the 167 footprints in public lands, only 30 are within the category of high restorable potential (RWI > 4.1), 74 of them are in the category of medium-high restorable potential $(3.6<$ RWI $<4.0), 45$ of them are in the category of medium-low restorable potential $(3.1<\mathrm{RWI}<3.5)$, and 18 of them are in the category of low restorable potential $(2.5<\mathrm{RWI}<3.0)$. In addition, among the total of 192 footprints with high restorable potentials (RWI > 4.1), the majority of them (162 footprints) are located on private land, which may have been included in prior conservation programs (e.g. Conservation Reserve Program). The variations have two implications for policy making. First, future wetland restoration and conservation efforts should still be focused on the 167 footprints

Table 1. The mean and standard deviation of each category of the Restorable Wetland Index

\begin{tabular}{lrrrrr}
\hline Restorable wetland index & Numbers & Percentage & Mean hectares & Standard deviation & Total hectares \\
\hline $2.5-3.0$ & 8,875 & $75.47 \%$ & 3.86 & 8.14 & $34,236.56$ \\
$3.1-3.5$ & 1,792 & $15.24 \%$ & 13.01 & 40.48 & $23,311.30$ \\
$3.6-4.0$ & 901 & $7.66 \%$ & 22.26 & 34.64 & $20,059.68$ \\
$4.1-5.0$ & 192 & $1.63 \%$ & 26.69 & 27.19 & $5,125.02$ \\
All & 11,760 & $100.00 \%$ & 7.03 & 21.00 & $82,732.55$ \\
\hline
\end{tabular}


in the public areas because of their higher mean RWI than that of the private lands. Second, future wetland restoration and conservation may need to consider the 162 highly restorable footprints (RWI > 4.1) in private lands. Because landowner information in the Conservation Reserve Program (CRP) is confidential, this study could not access the landownership database to identify footprints that have high potentials and are not involved in any wetland restoration programs. However, the federal, state, local wetland managers should be able to determine these footprints, prioritize them for field survey, and communicate with landowners.

\section{RWI and Footprint Size}

There is a statistically significant correlation between the RWI scores and size of footprints (Pearson product-moment correlation coefficient $r=0.296, P<0.01$ ), but the low coefficient means a weak correlation. In Table 1, it was noticed that wetlands with high RWI values had large mean hectare sizes. This result is expected because large footprints with historical hydric soil are often lands with ideal water conditions. Even with the obvious degradation of many wetlands in the Rainwater Basin region, larger footprints are often larger depressional lands, which have better chances to accumulate water. However, the low correlation coefficient and large standard deviations indicate that the internal variations are large. For example, the size range of the wetlands within the highly restorable category is $0.93-$ 128.44 ha with a standard deviation of 27.19 ha. This result reflects the heterogeneity of the Rainwater Basin wetlands when viewed at the landscape level. The policy implication of this finding is that wetland restoration should emphasize the restoration at the landscape scale and priority should be given to the footprints with high and medium-high restorable potentials.

\section{Conclusions}

The RWI provides a spatially explicit measure to identify wetlands potentially suitable for restoration for the entire Rainwater Basin region of south-central Nebraska. The RWI may be used to maximize the federal, state, and local investments in wetland restoration decisions and integrate solid scientific evidence into wetland management decisions. The prioritization of wetlands can improve wetland conditions through a comprehensive consideration of the watershed-level hydrologic restoration. The RWI improves upon traditional approaches that may only consider the static wetland information (e.g. soils, vegetation) by including the topographic depression conditions. In addition, this study further extends GIS-based wetland suitability assessments, which previously only applied to small scales (Abruzzes and Leibowitz 1997; Russell et al. 1997). The RWI result is based on each vector-based hydric soil footprint that provides site-specific description for all of the wetlands in the study area. This method further improves the rasterbased wetland suitability assessment models at the landscape scale proposed by White and Fennessy (2005). The specified indicators for each footprint can help wetland regulatory agencies assess the condition of each site. Many of the existing wetland project decisions were normally made on a project-by-project basis rather than at a larger landscape scale (White and Fennessy 2005). However, the wetland function is subject to the landscape level processes and ecosystem integrity. The overall RWI scores with measurable indicators will help wetland managers find solutions to improve wetland conditions at a landscape scale.

As is the nature of any research, limitations exist in this study. The RWI described herein only considers the physical environmental conditions of wetlands. It provides a scientific ranking based on an assessment of the natural conditions; however, due to the inaccessibility of the land ownership data and uncertainty of the construction costs, the RWI does not consider social, political, and economic variables. This study recognizes the importance of socioeconomic variables in comprehensive wetland restoration decisions. However, by excluding complex external factors and focusing solely on scientific aspects, results from this study may serve as an unbiased and independent tool to assist managers. Any wetland restoration decision must consider these socioeconomic variables such as land ownership, construction costs, stakeholder preference, collaboration willingness, and policy prioritization. While the RWI provides a useful ranking system, it cannot replace the need for on-site surveys. Field work and surveys by experienced ecologists, biologists, hydrologists, and wetland managers are still necessary to ensure a successful design and implementation of a wetland restoration program.

The RWI and periodization results can provide substantial benefits to future restoration decisions that reflect new restoration objectives. Socioeconomic variables were not considered in RWI because they are often site specific. For example the willingness of landowners to participate in potential wetland restoration programs would be difficult to measure in a scientific-oriented index system (Kauffman-Axelrod and Steinberg 2010). In fact, the RWI results could be informative to wetland managers to open a dialogue with landowners about restoration feasibility on their property. In addition, the visualized RWI maps convey important spatial information to the public, landowners, and wetland managers.

The RWI can provide a consistent, comprehensive, scientific approach to prioritize potential wetland restoration sites before going to the field. This approach could save wetland manager's valuable time and resources to achieve restoration objectives (Kauffman-Axlrod and Steinberg 2010). The prioritized wetland res- 
toration sites need field surveys and local knowledge assessment to determine if wetland restoration is feasible at a site level. The RWI provides a roadmap for wetland managers and others interested in gaining a quantitative view of wetland restoration conditions with a multi-criteria spatial assessment methodology.

Acknowledgments - This project was support by the U.S. Environmental Protection Agency (EPA) (Grant ID: \#CD97723501) and the Grant-In-Aid funds. None of the conclusions expressed here necessarily reflects views other than those of the authors. The research team sincerely appreciated the great support from the Rainwater Basin Joint Venture and the Nebraska Game and Parks Commission. The authors really appreciate the anonymous reviewers from Wetlands for their valuable comments and help in improving an earlier version of this article.

\section{References}

Abruzzes B, Leibowitz SG (1997) A synoptic approach for assessing cumulative impacts to wetlands. Environmental Management 21:457-475

Bedford BA (1996) The need to define hydrologic equivalence at the landscape scale for freshwater wetland mitigation. Ecological Applications 6:57-68

Bishop AA (2010) 2004-2009 Summary of habitat distribution and abundance throughout the Rainwater Basin wetland complex, U.S. Fish \& Wildlife Service, habitat and population evaluation team, Rainwater Basin joint venture

Bishop AA, Vrtiska M (2008) Effects of the wetland reserve program on waterfowl carrying capacity in the Rainwater Basin Region of South-Central Nebraska. A conservation effects assessment project wildlife component assessment

Carver S (1991a) Integrating multi-criteria evaluation with geographical information system. International Journal of Geographic Information System 5:321-339

Carver S (1991b) Site Search and multi-criteria evaluation. Planning Outlook 34(1):27-36

Cedfeldt PT, Watzin MC, Richardson BD (2000) Using GIS to identify functionally significant wetlands in the Northeastern United States. Environmental Management 26:13-24

Dahl T (2006) Status and trends of wetlands in the conterminous United States 1998-2004. U.S. Fish and Wildlife Service, Washington

Environmental Laboratory (1987) Corps of Engineers Wetlands Delineation Manual. Technical report Y-87-1. U.S. Army Corps of Engineers, Waterways Experiment Station, Vicksburg, MS

Fennessy MS, Jacobs AD, Kentula ME (2007) An evaluation of rapid methods for assessing the ecological condition of wetlands. Wetlands 27:543-560

Flanagan NE, Richardson CJ (2010) A multi-scale approach to prioritize wetland restoration for watershed-level water quality improvement. Wetlands Ecology and Management 18:695-706
Galatowitsh SM, van der Valk AG, Budelsky RA (1998) Decision-making for prairie wetland restorations. Great Plains Research 8:137-155

Haukos DA, Smith LM (1994) The importance of playa wetlands to biodiversity of the Southern High Plains. Landscape and Urban Planning 28:83-98

Hinton PR (1995) Statistics explained: a guide for social science students. Routledge, New York

Jacobs AD, Kentula ME, Herlihy AT (2010) Developing an index of wetland condition from ecological data: an example using HGM functional variables from the Nanticoke watershed, USA. Ecological Indicators 10:703-712

Kauffman-Axelrod JL, Steinberg SJ (2010) Development and application of an automated GIS based evaluation to prioritize wetland restoration opportunities. Wetlands 30:437-448

Kleinman D, Kupper L, Muller K (1988) Applied regression analysis and other multivariable methods. Duxbury Press, Belmont

Kramer L, Elliott M (2005) Identification of conservation opportunity areas in Georgia. GAP Analysis Bulletin 13:14-20

LaGrange TG (1997) Guide to Nebraska's Wetlands and their conservation needs. Nebraska Game and Parks Commission, Lincoln

LaGrange TG, Stutheit R, Gilbert M, Shurtliff D, Whited PM (2011) Sedimentation of Nebraska's Playa Wetlands: A review of current knowledge and issues. Nebraska Game and Parks Commission, Lincoln, p 62

Lin JP, Kleiss BA (2007) A wetland restoration spatial decision support system for the Mississippi Gulf Coast, U.S. Army Corps of Engineers, Engineer Research and Development Center, Environmental Laboratory, ERDC/FL TR-07-12

Liu C, Frasier P, Kumar L, Macgregor C (2006) Catchmentwide wetland assessment and prioritization using the multi-criteria decision making method TOPIS. Environmental Management 38:316-326

Mitsch WJ, Gosselink JG (1993) Wetlands. Van Nostrand Reinhold Co, New York, pp 578-579

Montgomery DR (2008) Dreams of natural streams. Science 319:291-292

National Research Council (NRC) (2001) Compensating for wetland losses under the Clean Water Act. National Academy of Sciences, Washington, DC, p 322

Nunnally JC, Bernstein HI (1994) Psychometric theory. McGrawHill, Inc, New York, pp 447-541

O' Hara CG, Davis AA, Kleiss BA (2000) A decision support system for prioritizing forested wetland restoration in the Yazoo Backwater Area, Mississippi, Water Resources Investigation Report 00-4199, U.S. Geological Survey

O'Neill MP, Schmidt JC, Dohbrowolski JP, Hawkins CP, Neale CMU (1997) Identifying sites for riparian wetland restoration: application of a model to the Upper Arkansas River Basin. Restoration Ecology 5:85-102

Possingham HP, Ball I, Andelman S (2000) Mathematical methods for reserve system design. In: Freson S, Burgman M (eds.) Quantitative methods for conservation biology. Springer, New York, pp 291-267

Robichaux RM (2010) Correlating climate with late-winter wetland habitat in the Rainwater Basin, South-Central Nebraska, Master Thesis, Kansas State University 
Robichaux RM, Harrington LMB (2009) Environmental conditions, irrigation reuse pits, and the need for restoration in the Rain Water Basin Wetland Complex, Nebraska. Papers of the Applied Geography Conferences 32:217-225

Russell GD, Hawkins CP, O’Neill MP (1997) The role of GIS in selecting sites for riparian restoration based on hydrology and land use. Restoration Ecology 5:56-68

Simenstad C, Reed D, Ford M (2006) When is restoration not? Incorporating landscape-scale processes to restore self-sustaining ecosystems in coastal wetland restoration. Ecological Engineering 26:27-39

Starks PJ (1984) Analysis of rainbasin depressions of Clay County, Nebraska, M.A., Thesis, Department of Geology/ Geography, University of Nebraska-Omaha

Stein ED, Dark S, Longcore T, Grossinger R, Hall N, Beland M (2010) Historical ecology as a tool for assessing landscape change and informing wetland restoration priorities. Wetlands 30:589-601

Steyer GD, Sasser CE, Visser JM, Swenson EM, Nyman JA, Raynie RC (2003) A proposed coast-wide reference monitoring system for evaluating wetland restoration trajectories in Louisiana. Environmental Monitoring and Assessment 81:107-117

Stralberg D, Applegate DL, Phillips SJ, Herzog MP, Nur N, Warnock N (2009) Optimizing wetland restoration and management for avian communities using a mixed integer programming approach. Biological Conservation 142:94-109
Stutheit RG, Gilbert MC, Whited PM, Lawrence KL (2004) A regional guidebook for applying the hydrogeomorphic approach to assessing wetland functions of Rainwater Basin depressional wetlands in Nebraska. ERDC/EL TR-04-4, U.S. Army Engineer Research and Development Center, Vicksburg

USFWS (U.S. Fish \& Wildlife Service) (1987) Soil-vegetation correlations in the sandhills and Rainwater Basin Wetlands of Nebraska. Biol Rep 87(11), September 1987, U.S. Fish \& Wildlife Service, U.S. Department of the Interior

USNRCS (U.S. Natural Resources Conservation Service) (2008) The Wetland reserve program supports migrating waterfowl in Nebraska's Rainwater Basin Region, CEAP conservation insight, September 2008

Voss K (2007) Mead Lake watershed wetland assessment project: Developing wetland landscape metrics for effective planning and adapting the Milwaukee River basin approach for a small agricultural watershed, Final Report to U.S. EPA- Region V. Wetland Grant \# CD 96511801

White D, Fennessy S (2005) Modeling the suitability of wetland restoration potential at the watershed scale. Ecological Engineering 24:359-377 